\title{
Use of Deep-frozen Human Cornea in Full-thickness Grafts
}

\author{
F. O. MUELLER,* M.D., L.A.H., D.o.; T. A. CASEY,* M.CH., D.o. \\ P. D. TREVOR-ROPER,* M.D., D.O.M.S., F.R.C.S.
}

[With Special Plate]

Brit. med. F., 1964, 2, 473-475

While a satisfactory technique for corneal grafting is now well established, there remains a universal shortage of donor eyes. It is never easy to arrange for the removal of eyes within a few hours of death, and in England our timid legislation has hindered rather than helped; but such eyes, although kept at $4^{\circ}$ C., become unsuitable for grafting after a few days, and the wastage is enormous. So for years research has continued to seek a way of permitting prolonged storage at low temperatures, with subsequent viability of the full corneal thickness. A technique is here described which seems at last to answer this problem. Nine cases of full-thickness homografts which had beer ciored at $-79^{\circ}$ C. for 10 to 29 days have now been observed, seven for over six months and two for over two months. Seven of the nine have been successful.

Lamellar or partial-thickness grafts, replacing only the anterior layers of the cornea, can remain optically clear even if there are no living cells in the donor cornea; and various methods of prolonged storage are thus practicable. But fullthickness grafts, necessary in the majority of cases where the corneal scarring extends more deeply, rarely remain clear unless the endothelium is intact and its cells are alive at the time of operation (Smith, 1962). Indeed these donor endothelial cells remain alive for at least a year (being of the same sex as their parents, as judged by counts of the proportions of nuclei containing the female sex chromatin body), unlike the donor epithelial cells, whether from fresh or frozen corneas, which are replaced within three to four weeks (Smith, personal communication, 1964).

A wide variety of cells and tissues of mammalian origin have been stored at low temperatures for long periods without loss of viability, in media containing glycerol or dimethyl sulphoxide (D.M.S.O.) (Smith, 1961). But full-thickness grafts from human cornea that had been kept in media containing glycerol at -40 to $-79^{\circ} \mathrm{C}$. have rarely remained optically clear (Eastcott et al., 1954 ; Rycroft, 1957 ; Stocker et al., 1960). Recently it was found that when eyes from rabbits and other mammals were suspended in media containing glycerol or D.M.S.O., neither substance could be detected in the aqueous humour in sufficient quantity to protect the endothelium during freezing and thawing. However, after injecting a suitable concentration of D.M.S.O. into the anterior chamber, the endothelial cells did survive freezing and thawing as judged by in vitro studies. On the other hand, the corneal epithelium tended to disintegrate when the eyes were suspended in media containing D.M.S.O., but remained intact after thawing if the eyes had been suspended in media containing glycerol before freezing (Smith et al., 1963). Experimental rabbit grafts also generally remained clear if the donor eyes were suspended in $10 \%$ glycerol, had their aqueous replaced by $7.5 \%$ D.M.S.O., and were then cooled to and kept at $-79^{\circ}$ C. for periods varying from a few hours to 114 days (Mueller and Smith, 1963 ; Mueller, 1964).

Now a limited number of human donor eyes have been

* From the Department of Ophthalmology, Westminster Hospital,
London. banked by the above method. The preliminary results of this first clinical trial are here described.

\section{Material and Methods}

A supply of 1-ml. sealed ampoules of pure D.M.S.O. and $2-\mathrm{ml}$. sealed ampoules of a $50 \%$ solution of glycerol in distilled water (sterilized by heating it to $130^{\circ} \mathrm{C}$. for one hour) were stored at room temperature. Fresh human plasma, supplied by the blood transfusion centre of Westminster Medical School, was diluted with an equal volume of Parker 199 tissue-culture medium, under sterile conditions; it was sealed in $20-\mathrm{ml}$. ampoules and stored at $-79^{\circ} \mathrm{C}$.

The human donor eyes were first examined to exclude corneal pathology and other abnormalities, and swabs of the conjunctiva were taken for bacterial culture. Immediately before preparation of the donor eyes for freezing and banking the two media were made up, containing respectively $7.5 \%$ D.M.S.O. and $10 \%$ glycerol in the $50 \%$ v.v. solution of human plasma-Parker 199. The anterior chambers of the intact donor eyes were irrigated with $4 \mathrm{ml}$. of the medium containing $7.5 \%$ D.M.S.O., using the technique described by Smith et al. (1963). The needle and its position in the donor eye is shown in Figs. 1a and $1 \mathrm{~b}$ (Special Plate). After irrigation the needle was withdrawn and the eyes were suspended in large glass tubes containing $5 \mathrm{ml}$. of the $10 \%$ glycerol solution. The tubes were sealed, using two fishtail burner flames. The eyes were cooled slowly to $-45^{\circ} \mathrm{C}$. at the rate of $1^{\circ}$ C. per minute, using the Pegg cooling apparatus (Pegg and Trotman, 1959). The whole process of freezing took approximately 70 minutes. The eyes were then transferred to the deep-freeze bank, and kept in a mixture of alcohol and solid $\mathrm{CO}_{2}$ at $-79^{\circ} \mathrm{C}$. for varying periods of time. A frozen eye is illustrated in Fig. 3 (Special Plate).

Thawing of Donor Eyes.-On the day of operation selected eyes were brought to the operating-theatre in Dewar flasks containing alcohol and solid $\mathrm{CO}_{2}$. The eyes were quickly thawed out at the beginning of the operation. The ampoules were opened by encircling them with a red-hot wire (Special Plate, Fig. 2). After approximately two and a half minutes in a water-bath at $+55^{\circ} \mathrm{C}$. all ice attached to the cornea had melted, and the eyes were taken out of the glass tubes and gently washed with the recipient's own serum. A thawed-out donor eye is shown in Fig. 4 (Special Plate). The cornea was examined and the full-thickness corneal disk cut with a 7-mm. trephine. The graft was placed in a Petri dish with its epithelial surface downwards, and one drop of the patient's serum was placed on the endothelium. A swab for bacterial culture was taken from the remaining cornea and conjunctiva of the donor eye.

Pre-operative Treatment and Surgical Technique.-Seventytwo hours before the operation bacterial cultures were taken from both lower fornices, of the patient. The nasolacrimal ducts were syringed to ensure patency, and thereafter chloramphenicol drops were instilled. Provided the culture report was negative, a $2 \%$ aqueous solution of pilocarpine was instilled at 15 -minute 
intervals for two hours before operation. $10 \mathrm{ml}$. of venous blood was taken from the patient, and the serum separated. The operation was performed under general anaesthesia. The patient's eye was prepared and the cornea cut with a $7-\mathrm{mm}$. trephine, the section being completed with scissors after the anterior chamber had been opened. The previously prepared donor disk was immediately sutured into the bed of the recipient cornea, using a 4-mm. Oertli needle and Oertli silk. During the operation the eye was kept moist by applications of the patient's own serum. At the end of the operation air was injected into the anterior chamber, and in most cases mydricaine (Moorfields No. 2) was injected subconjunctivally. Atropine and chloramphenicol ointments were placed in the lower fornices, and both eyes were padded and bandaged.

Post-operative Treatment and Removal of Sutures.-The eyes were dressed and examined two to three times weekly. Some eyes were treated with drops of atropine, chloramphenicol, and hydrocortisone, others with atropine and Neo-Cortef ointments only. All patients were given tab. Diamox (tab. acetazolamide) $250 \mathrm{mg}$. b.d. for two to three weeks after operation; some also received tab. prednisolone $5 \mathrm{mg}$. b.d. for two to three weeks after the first week. The sutures were removed under general anaesthesia during the fourth post-operative week. A subconjunctival injection of hydrocortisone was given at the same time.

\section{Ocular Conditions before Surgery}

Case 1.-A man of 63 who had been under treatment for eyeirritation ever since a sand-blast injury 15 years previously. Both corneas showed epithelial and stromal oedema, with some vascularization.

Case 2.-A woman of 49 whose left eye had sustained a limeburn 15 years previously. The affected cornea showed a dense scar over the lower and part of the upper nasal quadrant, with trunk vascularization. The upper temporal quadrant showed early bandshaped degeneration.

Case 3.-A man of 50 with interstitial keratitis; active and ghost vessels were evident in the semi-opaque cornea.

Case 4.-A woman of 52 who had suffered from recurrent corneal ulceration since childhood. The left corneal opacities extended into the deeper layers of the stroma as well as to the periphery; fine vessels reached all layers of the stroma (Special Plate, Fig. 5).

Case 5.-A boy of 15 with bilateral keratoconus. The conus of one eye was very thin and opaque.

Case 6.-A man of 58 with bilateral keratoconus. The conus of one eye was very thin and opaque.

Case 7.-A man of 49 with a history of recurrent corneal ulcers of one eye since 1944. A lamellar graft had been performed in 1957. It was subsequently replaced by a full-thickness graft because of recurrent ulcers and deep vascularization, but this graft had also became opaque from ulceration.

Case 8.-A woman of 51 who had been treated for recurrent ulcers of her left cornea since 1945. A lamellar graft had been performed in 1961 , but in 1962 it had to be replaced by a fullthickness graft because of persistent oedema. This graft later became ectatic and opaque.

Case 9.-A woman of 73 had already had two grafts for recurrent ulcers of the right eye. Although the second graft remained clear, a post-graft membrane made a further operation necessary.

\section{Results}

Donor Eyes after Thawing.-The epithelium of all donor eyes was intact and regular ; the stroma was clear and of normal thickness. The anterior chamber of all donor eyes was of good depth and free of ice. The lens and vitreous body, however, were still frozen solid (Special Plate, Fig. 4). The stroma of the excised disks appeared clear; the edges we.e sharp and the cut was regular in six, but in Nos. 1, 2, and 3 the edges were irregular in part of their circumference. Two disks had pigment attached to the endothelial surface (Nos. 3 and 4). The endothelium of graft No. 1 appeared slightly folded over in one quadrant. At the end of the operation the epithelium of seven grafts was regular and intact, but in two cases it was irregular (Nos. 3 and 8). The stroma was still clear and of normal thickness. Fine wrinkles in the deeper layers of the stroma and Descemet's membrane could be seen in three grafts (Nos. 1, 3, and 8).

Observation during First Month after Operation.-During the first few days after operation the epithelium of all transplants was irregular, but at no time did Bowman's membrane become denuded of its epithelium. The stroma of all transplants remained of normal thickness until the end of the first post-operative week, when it thickened slightly. During the first 10 post-operative days the wrinkles in the deepest layers of the stroma remained unaltered (Nos. 1, 3, and 8), and the pigment attached to the endothelium of two grafts remained visible (Nos. 3 and 4). At the end of the second post-operative week the epithelium over all transplants became oedematous, the stroma increased visibly in thickness, and the graft showed a fine haze. At this time all grafts developed wrinkles in the deep layers of the stroma and in Descemet's membrane.

Observations during Second Month after Operation.-The epithelium and stroma of five grafts rapidly became less swollen and the opaque lines in the deep stroma became less and less conspicuous (Nos. 4, 5, 6, 7, and 9). At the end of the second month two grafts were clear in all layers (Nos. 5 and 6), and three were clear in parts (Nos. 4, 7, and 9). Two showed reduction of oedema (Nos. 2 and 8), and two remained waterlogged (Nos. 1 and 3). The striae in the deep stroma of graft No. 1 became more and more dense and increased in width and length, and the interspaces between the striae slowly became opaque.

Observations during Third Month and Thereafter.-Two grafts (Nos. 5 and 6) remained clear and a further two (Nos. 4 and 7) became and stayed clear from the fourth month onwards. Because of lens opacities the visual result of graft No. 6 remained unsatisfactory (see Table and Special Plate, Figs. 6, 7,8 , and 9). The foreign pigment attached to the endothelial surface of graft No. 4 gradually disappeared. Graft No. 2 progressed slowly. Although the centre of the graft and part of the periphery were now clear, there was still some residual oedema, due in part at least to the multiple anterior synechiae at the host-graft junction. A contact-lens trial has not yet been possible because of the oedema. The visual result with glasses has been disappointing (see Table). The epithelium of graft No. 1 remained oedematous throughout the three months of observation, and large bullae appeared from time to time. A complete post-graft membrane adherent to the graft became obvious during the fourth post-operative month, and later showed the typical ripples due to the contraction of fibrous tissue. Graft No. 3, although still oedematous, developed no post-graft membrane and the stroma has shown a reduction of oedema during the last weeks. The epithelium, however, was still oedematous. Vascularization of graft No. 1 developed in the fourth month after operation.

\section{Discussion}

These human donor eyes were prepared, frozen, and banked at $-79^{\circ} \mathrm{C}$. Only eyes that had been banked within five hours of death were later used for full-thickness corneal grafts.

Human plasma and tissue-culture medium were used to dilute the protective agents in preference to Ringer's solution and normal saline, because in vitro studies on the rabbit cornea had shown that physiological salt solutions alone harmed the endothelium. Furthermore, in grafting rabbit eyes the use of normal saline for wetting the graft and the recipient eye usually caused 


\section{F. O. MUELLER ET $A L$.: USE OF DEEP-FROZEN HUMAN CORNEA}
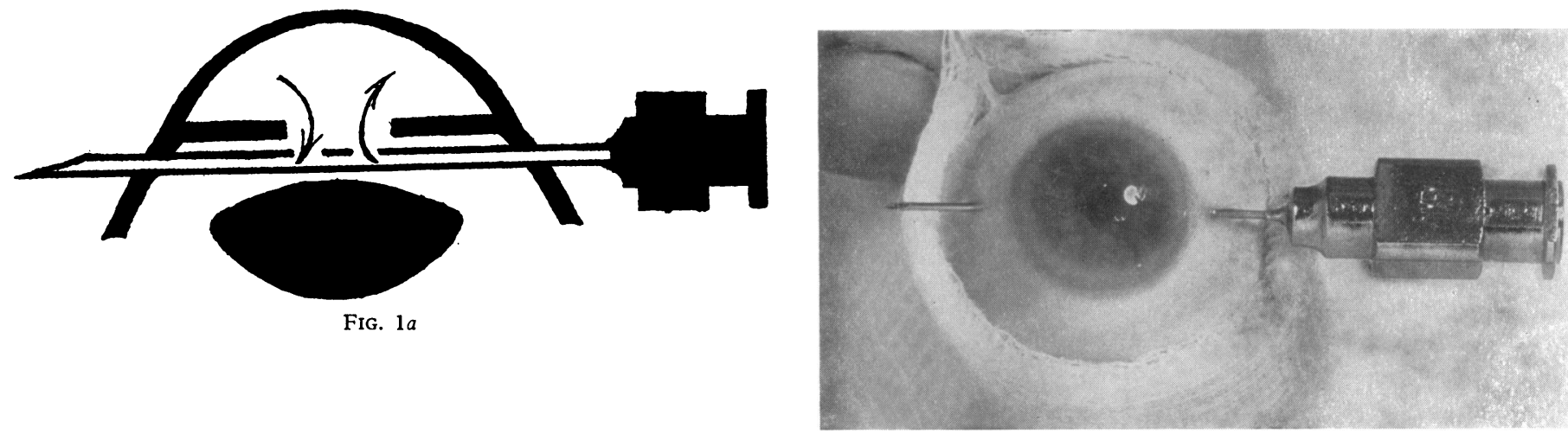

Fig. $1 b$

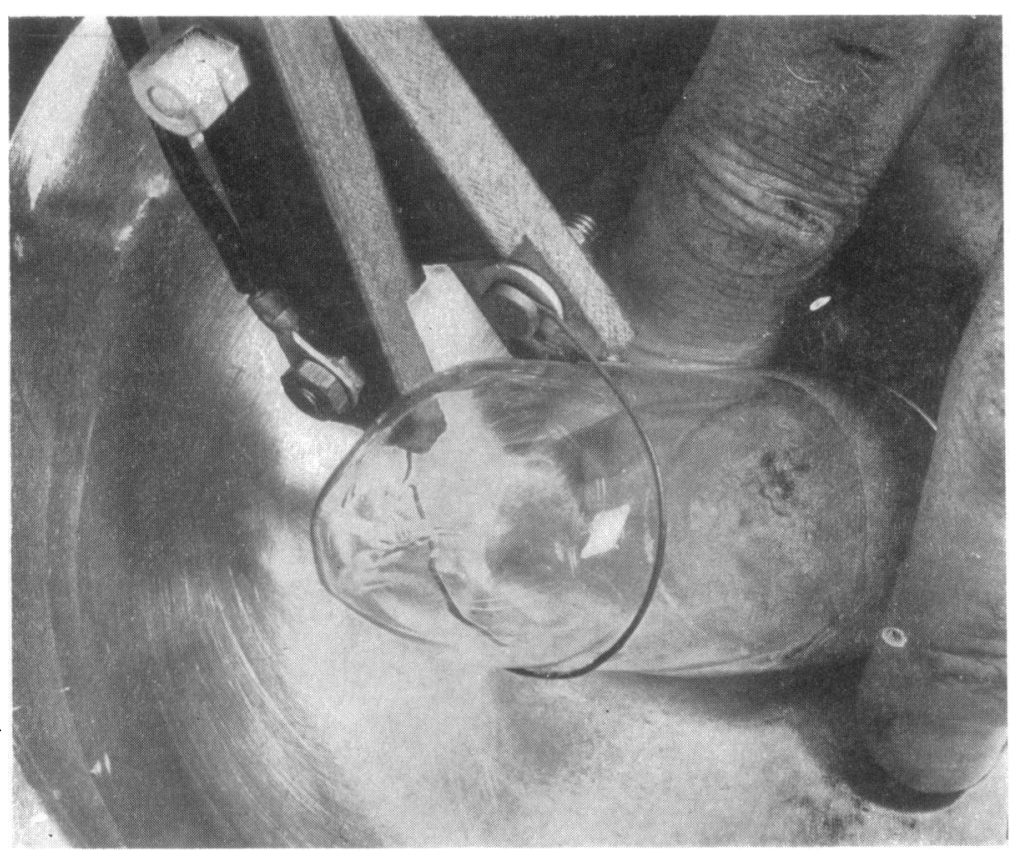

FIG. 1.-Preparation of donor eye for freezing and banking. (a) Diagram showing the irrigation needle in position. (b) The needle across the anterior chamber behind the iris diaphragm.

FIG. 2.- Thawing of donor eye in beaker containing water at $+55^{\circ}$ C. A heated wire encircles the glass tube ready to open the ampoule.

FIG. 2

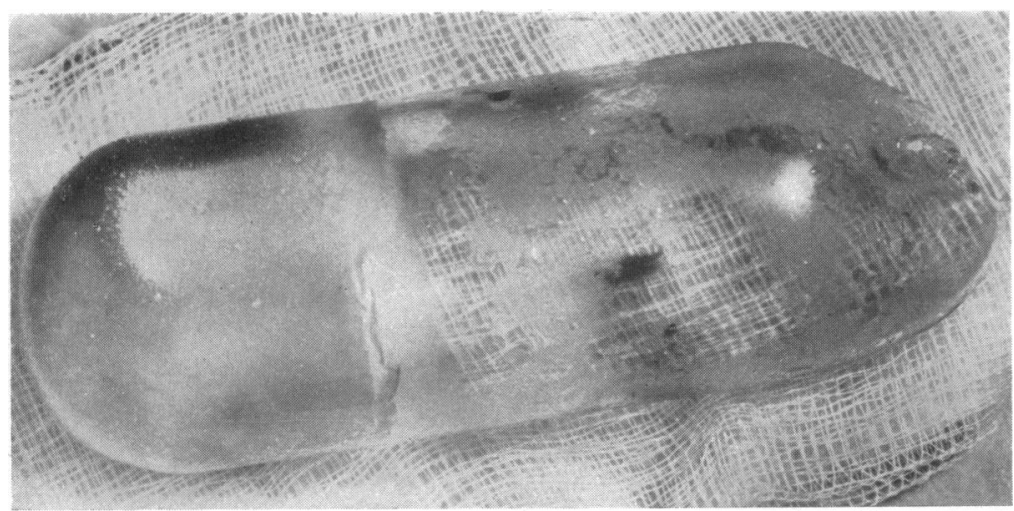

FIG. 3

Fig. 3.-Donor eye frozen in its suspending medium at $-79^{\circ} \mathrm{C}$. in sealed glass tube.

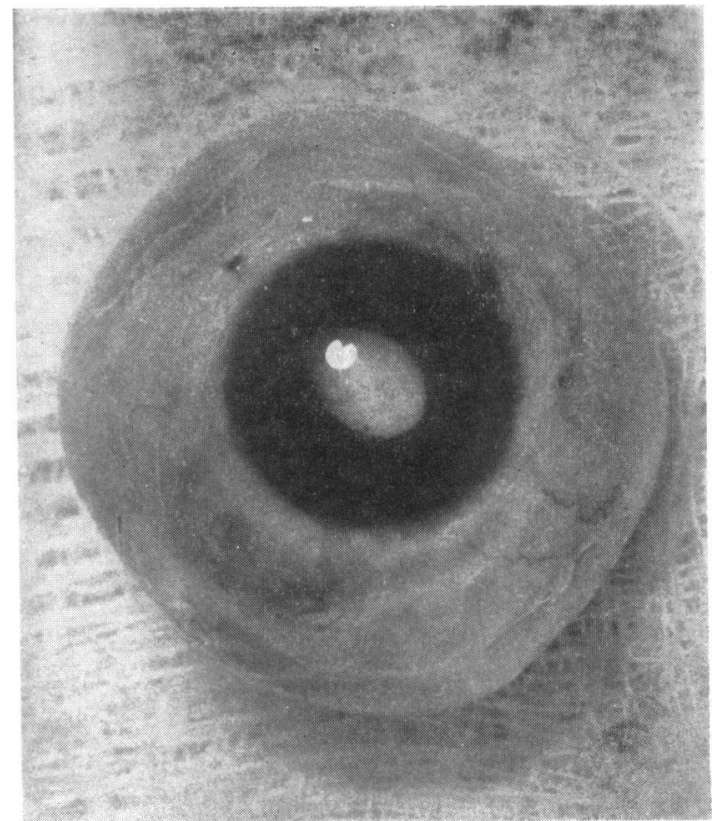




\section{F. O. MUELLER ET $A L$.: USE OF DEEP-FROZEN HUMAN CORNEA}

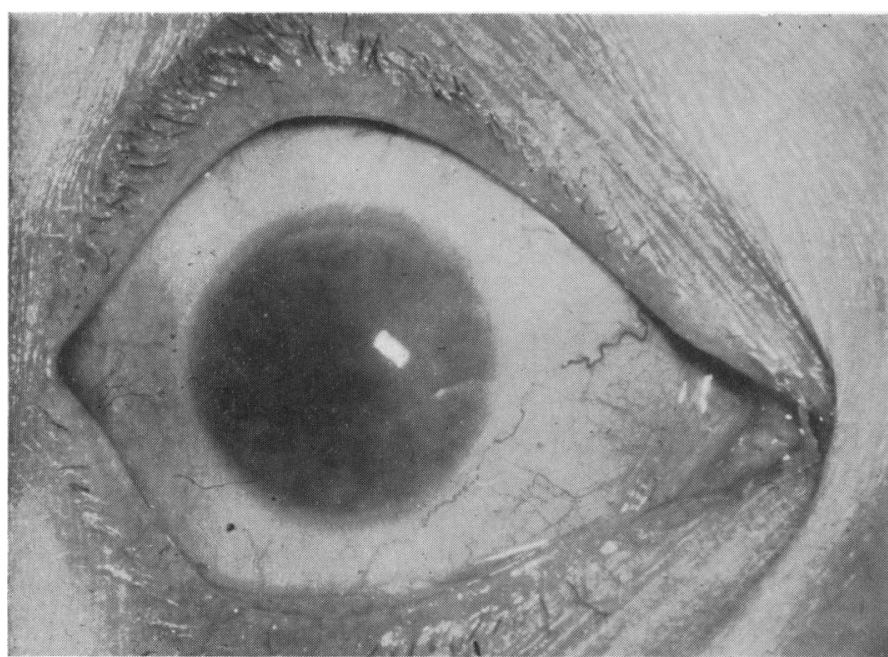

Fig. 5.-Case 4. Recipient eye before full-thickness corneal graft.

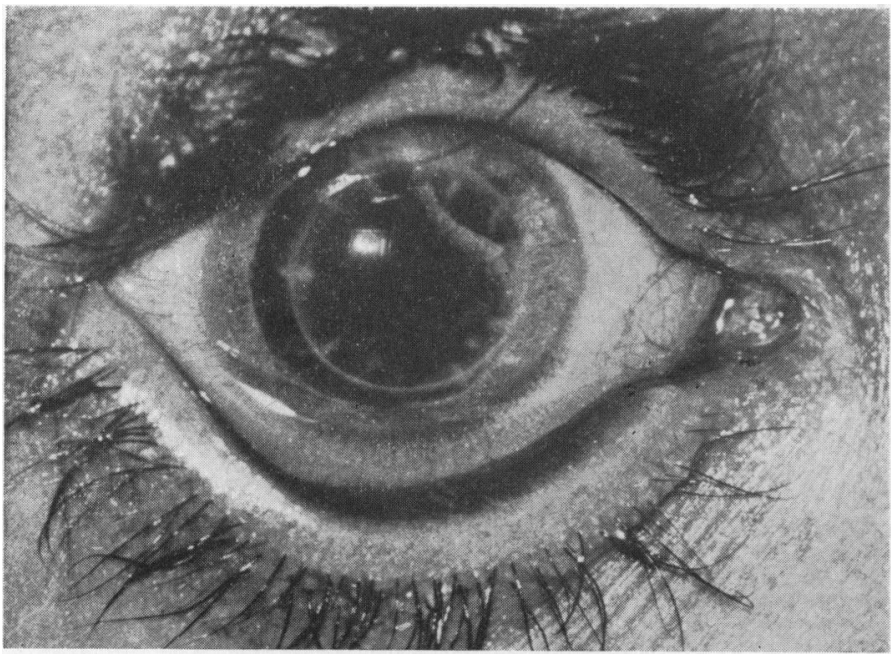

FIg. 7.-Case 5. Full-thickness corneal graft with material kept for 19 days at $-79^{\circ} \mathrm{C}$. Twenty-four weeks after operation.

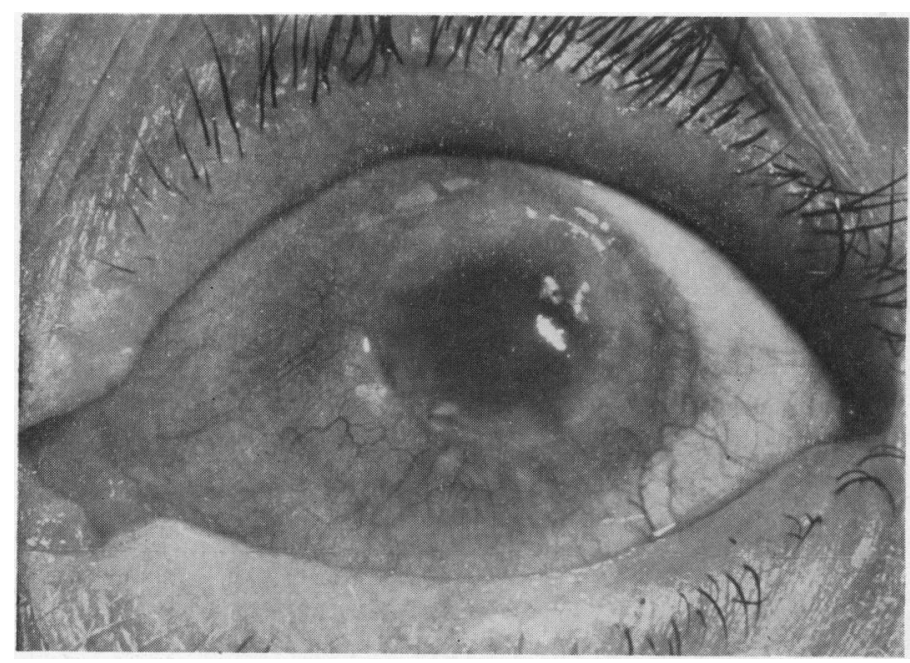

Fig. 9.-A 7-mm. full-thickness graft in a lime-burn case 22 weeks after operation. Material kept for 16 days at $-79^{\circ} \mathrm{C}$.

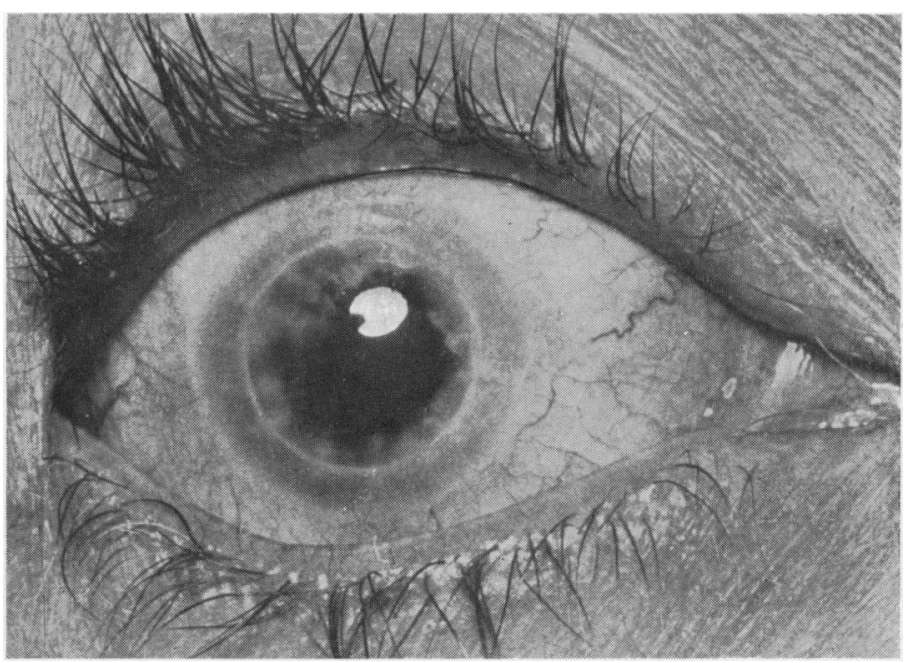

FIG. 6.-Case 4. A 7-mm. full-thickness graft with material that had been banked for 13 days at $-79^{\circ} \mathrm{C}$. Twelve weeks after operation.

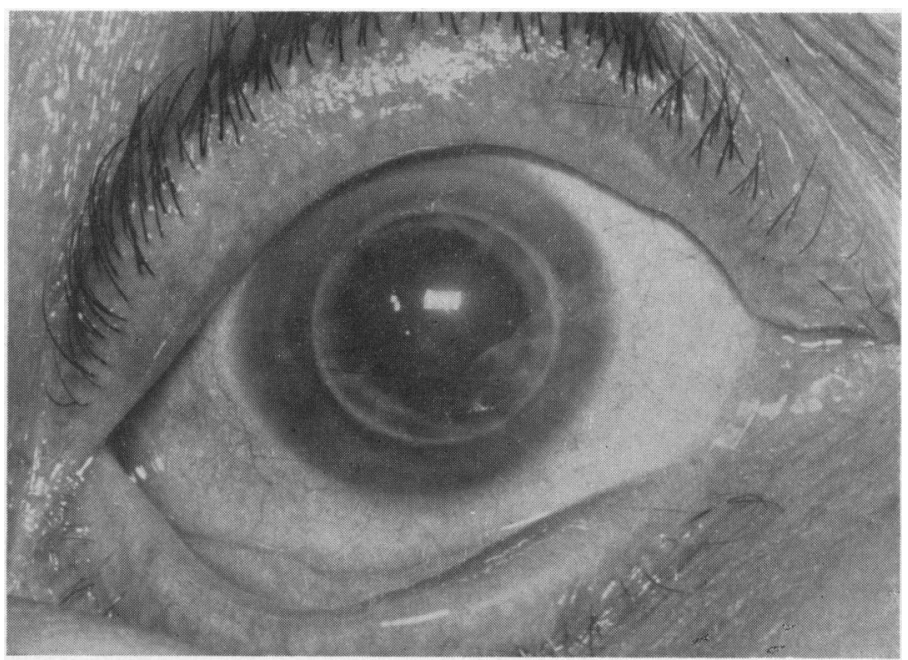

FIG. 8.-Case 6. Full-thickness corneal graft with material banked for 29 days. Twenty weeks after operation.

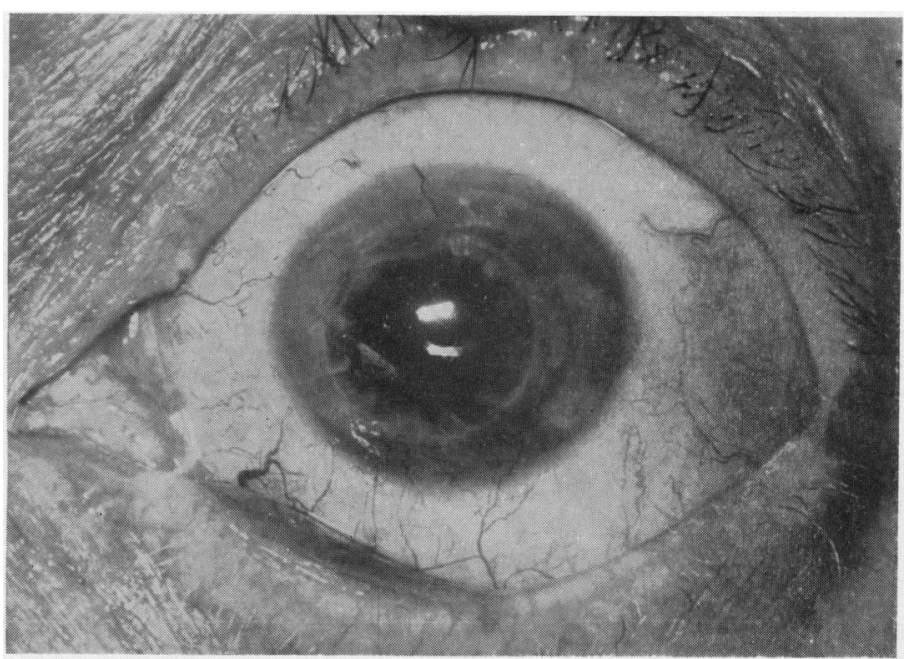

FIG. 10.-Case 4. Full-thickness corneal graft with material stored for 29 days at $-79^{\circ}$ C. 21 weeks after operation. 
Frozen Human Donor Eyes Injected with $7.5 \%$ Dimethyl Sulphoxide, Suspended in $10 \%$ Glycerol at $79^{\circ}$ C. and their Results After Full-thickness Grafting

\begin{tabular}{|c|c|c|c|c|c|c|c|c|c|c|c|}
\hline \multicolumn{6}{|c|}{ Donor Details } & \multicolumn{6}{|c|}{ Recipient Details } \\
\hline \multirow{2}{*}{$\begin{array}{l}\text { Serial } \\
\text { No. }\end{array}$} & \multirow{2}{*}{$\begin{array}{c}\text { Banked } \\
\text { after } \\
\text { Death } \\
\text { (hr., min.) } \\
\end{array}$} & \multirow{2}{*}{$\begin{array}{c}\text { Dura- } \\
\text { tion of } \\
\text { Storage } \\
\text { (days) }\end{array}$} & \multicolumn{2}{|c|}{$\begin{array}{l}\text { Cultures } \\
\text { from Eyes }\end{array}$} & & \multirow{2}{*}{$\begin{array}{l}\text { Ocular Condition for which Graft } \\
\text { was Performed }\end{array}$} & \multirow{2}{*}{$\begin{array}{l}\text { Pre-op. } \\
\text { Vision }\end{array}$} & \multicolumn{2}{|c|}{ Surgical Results } & \multicolumn{2}{|c|}{ Optical Results } \\
\hline & & & \begin{tabular}{|c|} 
Before \\
Banking
\end{tabular} & $\begin{array}{c}\text { After } \\
\text { Banking }\end{array}$ & & & & $\begin{array}{c}2 \\
\text { months }\end{array}$ & $\begin{array}{c}6 \\
\text { months }\end{array}$ & Dist. & Near \\
\hline$\frac{1}{2}$ & $\begin{array}{l}3.15 \\
3.15\end{array}$ & $\begin{array}{l}10 \\
16\end{array}$ & $\overline{-}$ & $\overline{-}$ & \} $\begin{array}{l}\text { Pair of donor } \\
\text { eyes }\end{array}\{$ & $\begin{array}{l}\text { Post-traumatic opacities } \\
\text { Limeburn }\end{array}$ & $\begin{array}{l}\text { H.M. } \\
\text { H.M. }\end{array}$ & $\begin{array}{l}0 \\
+\end{array}$ & $\stackrel{0}{++}$ & $6 / 60$ & $\mathrm{~N} 24$ \\
\hline $\begin{array}{l}3 \\
4 \\
5 \\
6 \\
7 \\
8 \\
9\end{array}$ & $\begin{array}{l}4.30 \\
4.30 \\
3.00 \\
2.10 \\
2.10 \\
1.50 \\
2.00\end{array}$ & $\begin{array}{l}15 \\
13 \\
19 \\
29 \\
29 \\
28 \\
14\end{array}$ & $\begin{array}{l}\bar{z} \\
\pm \\
\bar{z}\end{array}$ & $\begin{array}{l}\bar{z} \\
\bar{z} \\
\bar{z}\end{array}$ & $\begin{array}{l}\left\{\begin{array}{l}\text { Pair of donor } \\
\text { eyes }\end{array}\right. \\
\begin{array}{l}\text { Pair of donor }\{ \\
\text { eyes }\end{array}\end{array}$ & $\begin{array}{l}\text { Interstitial keratitis } \\
\text { Keratitis } \\
\text { Keratoconus } \\
\text { Keratoconus } \\
\text { Regroft for recurrent ulcers } \\
\text { Failed graft, fibrosis } \\
\text { Failed graft, post-graft membrane }\end{array}$ & $\begin{array}{l}\text { H.M. } \\
\text { C.F. } \\
6 / 60 \\
1 / 60 \\
\text { H.M. } \\
\text { H.M. } \\
\text { H.M. }\end{array}$ & $\begin{array}{l}0 \\
++ \\
++ \\
++ \\
++ \\
++\end{array}$ & $\begin{array}{l}0 \\
+++ \\
+++ \\
+++ \\
++ \\
+\end{array}$ & $\begin{array}{l}6 / 9 \\
6 / 6 \\
6 / 66 \\
6 / 6\end{array}$ & $\begin{array}{l}\text { N5 } \\
\text { N4 } \\
\text { N8 } \\
\text { N4 }\end{array}$ \\
\hline
\end{tabular}

$0=$ Diffuse oedema of stroma and epithelium. $+\omega=$ Minimal oedema of stroma and epithelium. $++=$ Partially clear graft. $+++=$ The entire graft clear in all layers. * At time of writing interval less than 3 months. H.M. $=$ Hand movement. C.F. $=$ Counts fingers.

oedema of the epithelium and stroma, while rabbit serum applied to the graft and the eye caused no oedema. So the patient's own serum was used in our trial to moisten both graft and eye during operation.

The cornea of both human and rabbit eyes was found to be impermeable to glycerol and to D.M.S.O. In the intact human eye the cornea therefore formed a natural barrier, enabling us to use the appropriate reagent, glycerol, to protect the epithelium and D.M.S.O. to protect the endothelium during freezing and thawing.

It was interesting to note that all donor eyes were clear after thawing. Intrastromal air-bubbles as described by Rycroft (1957) were not detected. Air in the anterior chamber of one donor eye was noticed before freezing and after thawing. The air had been injected accidentally into the anterior chamber during the irrigation of the donor eye, but did not seem to have harmful effects (Case 4). When cutting the disk from the thawed-out donor eye great care was taken to keep the endothelium intact. On several occasions, however, the anterior chamber collapsed and the endothelium came into contact with either iris or frozen lens. Damage to the endothelium by rubbing it against the underlying structures might have caused the failure of two grafts which remained cloudy. The collapse of the anterior chamber was due to pressure of the trephine while cutting the graft, causing leakage of fluid from the anterior chamber through the scleral punctures (previously made by the irrigating needle-Figs. $1 \mathrm{a}$ and $1 \mathrm{~b}$ ). So, in the eyes that were banked subsequently the punctures were sealed by cautery before freezing, or the loss of fluid was prevented by closing the holes with the index finger and thumb of one hand during trephining.

Only 7-mm. trephines were used, and the donor disks were placed into their prepared beds and sutured to clear cornea. Smaller grafts fixed by a corneal splint with indirect overlay sutures would reduce handling of the graft and might give better results.

Although the number of grafts performed is small, our results indicate a higher success rate than the methods previously used for prolonged storage of human corneal tissue for full-thickness grafts. The behaviour of the deep-frozen material does not appear to differ from that of fresh donor material so long as it is treated and handled appropriately and the cases are selected carefully. Although the failures in our series are most likely the result of damage to the endothelium during cutting and suturing of the donor disks, the presence of a non-viable endothelium after thawing cannot be excluded. It is, however, interesting to note that in the two failures the donor disks were not only cut from different pairs of eyes but that the second eye of each pair gave a good result (see Table). This suggests that the endothelium of all four donor eyes survived cooling to, banking at, and thawing from $-79^{\circ} \mathrm{C}$.

Our lnowledge about the thawed human cornea is still very incomplete, and further in vitro tests and tissue-culture experiments are planned.
In the series presented donor eyes were preserved for periods of 10 to 29 days, whereas rabbit eyes that had been kept for periods of up to 114 days at $-79^{\circ} \mathrm{C}$. gave good results ; further investigations will show if there is a time-limit for the lowtemperature storage of human donor eyes for full-thickness keratoplasty.

\section{Summary}

There is a universal shortage of donor eyes for corneal grafting in Britain, and even those that are obtained within a few hours of death are often wasted because they become unsuitable for use after several days' storage at $4^{\circ} \mathrm{C}$. A technique is now reported in which grafts of full corneal thickness are stored at $-79^{\circ} \mathrm{C}$. These grafts have proved viable after storage of up to 29 days.

Donor eyes were injected with a solution containing $7.5 \%$ dimethyl sulphoxide and then suspended in a medium containing $10 \%$ glycerol. They were sealed in ampoules and slowly cooled to and banked at $-79^{\circ} \mathrm{C}$. After storage for periods of 10 to 29 days they were thawed out rapidly and used for fullthickness homografts. Nine cases are described, seven of which have been observed for over six months ; five of the seven grafts have been successful. The remaining two (now in their third post-operative month) promise well.

It is suggested that the two failures are attributable to the normal operative hazards, and that this method will form a basis for the widespread saving of donor material and the use of deep-frozen donor eyes where fresh material is not available.

We are indebted to Dr. K. A. Newton and the staff of the Radiology Department of Westminster Hospital for allowing us to use their cooling and banking equipment, and particularly to Dr. D. E. Pegg for his help and advice. We should also like to thank Dr. D. James of the Blood Transfusion Centre at Westminster Medical School; Mr. H. S. Grainger, Chief Pharmacist of Westminster Hospital, and his department for help in preparing the media ; and Dr. P. Hansell's Medical Illustration Department at Westminster Medical School for the excellent illustrations. We gratefully acknowledge the help of Mrs. V. Hammond in many ways apart from that as secretary to the Ophthalmic Department, and the co-operation of the nursing staff in our ophthalmic wards.

\section{REFERENCES}

Eastcott, H. H. G., Cross, A. G., Leigh, A. G., and North, D. P. (1954). Lancet, 1, 237 .

Mueller, F. O. (1964). Brit. F. Ophthal., 48, 377.

and Smith, A. U. (1963). Exp. Eye Res., 2, 237.

Pegg, D. E., and Trotman, R. E. (1959). 7. clin. Path. 12, 477.

Pegg, D. E., and Trotman, R. E. (1959). F. clin. Path., 12, 477.

Rycroft, B. W. (1955). Corneal Grafts.

Smith, A. U. (1961). Monogr. Physiol. Soc., No. 9.

(1962). Int. Ophthal. Clin., 2, 731.

Ashwood-Smith, M. J., and Young, M. R. (1963). Exp. Eye Res., 2, 71 .

Ștocker, F. W., Matton, M. Th., Eiring, A., Georgiade, R., and Georgiade, N.. (1960), Amer. J.' Ophthal., 49, 729. 